\title{
Merleau-Ponty, Passivity and Science: From Structure, Sense and Expression, to Life as Phenomenal Field, via the Regulatory Genome ${ }^{1}$
}

David Morris, Department of Philosophy, Concordia University, David.Morris@concordia.ca

concordia.academia.edu/DavidMorris

Submitted version. Published in Chiasmi International: Trilingual Studies Concerning Merleau-Ponty's Thought 14 (2012): 89-111.

\begin{abstract}
I argue that something more is at stake in Merleau-Ponty’s engagement with science than a mere dialectic with another discipline. This is because his methodological commitments end up positioning science as a special resource for pursuing deep ontological concerns that increasingly haunt his philosophy. I show this by connecting points in the Phenomenology's "Phenomenal Field" chapter to his methodological challenge to the view that philosophy begins from a wholly active, autonomous, reflective consciousness. I link this to issues of passivity in a way that reveals science as a potential resource for grasping reflection not as autonomous, but as an operation of and within the phenomenal field-as radical reflection. Via critical analysis of recent results about the regulatory genome, I then show how current embryology can help us conceptualize life as a phenomenal field that implicitly engenders the sorts of revelatory operations distinctive of phenomenality. This lets us position phenomenology not merely as a reflection on phenomena from above, but as a radical reflection that operates through an 'older' phenomenality of life. This also give insights into some difficult issues in Merleau-Ponty’s later philosophy, by suggesting a new route to them through combining his earlier philosophy with recent science.
\end{abstract}

An obvious and remarkable feature of Merleau-Ponty’s philosophical work, from the 1942 Structure of Behaviour (SB), through the 1945 Phenomenology of Perception (PhP), the child psychology lectures (1949-52), and on to his later lecture courses on institution and passivity (IP, 1954-55) and nature (LN, 1955-56) is his continual engagement with science. ${ }^{2}$ What motivates his engagement with science and what is at stake in it? ${ }^{3}$ One well known motivation is methodological, namely his way of pursuing philosophical critique through dialectical engagement with other positions-including scientific positions. But I want to show how deeper issues are at stake, by indicating how the methodological motives that drive Merleau-Ponty to engage specifically with science (and not just, say philosophy or art) also end up positioning science as a special resource for pursuing the ontological issues that are his increasing concern. (Here and throughout, by science, I mean "natural science," not the more expansive French "science" or German "Wissenschaft," which would already include phenomenology, and thus throw off our question.)

To show this, the first section studies some points in the "Phenomenal Field," a key yet often underplayed chapter and concept in the Phenomenology. ${ }^{4}$ This study connects his methodological motives for engaging science with his challenge to the view that philosophy begins from a wholly active, autonomous, reflective consciousness already constituted at a remove from its object and even from itself. Philosophy on the contrary entails what MerleauPonty calls "radical reflection," in which philosophical reflection is a joint operation of the reflector and the being the reflector reflects upon. (In VI this turns into the concept of "hyperreflection”.) I show how the phenomenal field chapter links radical reflection to issues of passivity $^{5}$ that would in turn position science as a potential resource for grasping reflection not as autonomous, but as an operation of and within the phenomenal field - as radical reflection. (For clarity, I distinguish below between the reflector whose putative autonomy Merleau-Ponty challenges, and reflection as a joint operation of the reflector and being.)

The science of Merleau-Ponty's time, however, did not quite let him make this move of installing reflection in being via the phenomenal field. In the second section, I will show how recent embryology can in fact help us conceptualize life as a phenomenal field. That is, science 
can help us encounter life as a field in which we find (implicitly) engendered the sorts of revelatory operations distinctive of phenomenality, such that phenomenology is not merely reflection on phenomena by a reflector from above, but operates through an 'older' phenomenality of life. ${ }^{6}$

Since the ontological and conceptual innovations of The Visible and the Invisible are geared to this installation of reflection in being, and since his studies of embryology in various places in the lectures on institution and nature are contributory to these innovations, my procedure will give insight into some difficult issues in Merleau-Ponty's later philosophy by suggesting a new route to them through combining his earlier philosophy with recent science-a route that Merleau-Ponty might have pursued had he lived long enough to encounter new discoveries in the life sciences. My procedure it also exposes science as a potentially deep resource for Merleau-Ponteian philosophy.

\section{1) From Radical Reflection to Science, via Passivity and the Phenomenal Field}

To appreciate what is methodologically and ontologically at stake in the "Phenomenal Field" chapter, let me first situate the Phenomenology within Merleau-Ponty's philosophical project, and then situate the "Phenomenal Field" chapter within the project of the Phenomenology.

Structure sets out to investigate the relations between nature and consciousness, so as to undo traditional dualisms. The problem is how to bring meaning and matter together. This is the problem of what Merleau-Ponty (in the Phenomenology) calls sense, a meaning that is inseparable from its bodily and material manifestation. ${ }^{7}$ In Structure Merleau-Ponty discovers sense in the phenomenon of structure, which entails the "joining of an idea and existence that are indiscernible.” 8 Specifically, he discovers structures in the observable physical, organic and social world. A philosophy of living structure could thus undo the ontological dualism of nature and consciousness, since living structures are irreducibly material and meaningful. But Structure raises the question whether sense is in our experience of structures only, or is in structures themselves-whether structure as the location of sense is just an artefact of our cognition and therefore not a robust way out of ontological dualism. This question is what leads Merleau-Ponty to the project of the Phenomenology, which in effect tackles the problem of the location of sense, through a rigorous, phenomenological investigation of experience and the experiencer/reflector who perceives structure in things. If the Phenomenology can show that phenomenologically rigorous descriptions of experience themselves point to structure, as delineated by something beyond our constituting operations, something that engenders its own sense, then sense and structure can serve as a way into a non-dualist ontology.

Notice the methodological issue here: if, in the Phenomenology, it is merely operations of the reflector that delineate sense and structure, then the problem of Structure remains. Indeed, it is the view of many scholars that the Phenomenology does not escape this problem (a point returned to below), or that, even worse, the Phenomenology's turn to Husserlian subjectivity betrays the more radical sense that the Structure detected in living organisms as structures. ${ }^{9}$ This is why there is so much at stake, from the very start of the Phenomenology, in the concept of radical reflection: if the reflective operations that delineate structure are not merely operations of the lived, bodily subject, but operations in and of a deeper and broader phenomenal field, then there is hope of resolving Structure's ontological problem. I want to show how the concept of the phenomenal field can, through attention to passivity and science, open a path to this sort of resolution. 
To trace this path, and science's role in it, I now turn to the preface of the Phenomenology, for this famously begins by insisting that a thoroughly rigorous science entails an analysis of the perceptual being through which alone one is in the world as a scientific knower. Methodologically, this sets things in motion toward the phenomenal field, by motivating a phenomenological analysis of the body as a key site and object of scientific knowing. The first three chapters of the introduction pursue this via a preliminary analysis that unfolds as a dialectical critique of science's own claims about the body, anticipating the Phenomenology's overall result that science is in fact rooted in a pre-reflective lived body and expressive tradition that is irreducible to a classic object of scientific reflection. This reinstalls scientific knowing in pre-reflective structures of being. The fourth and final introductory chapter, "The Phenomenal Field," formalizes this reinstallation as a return to a phenomenal field. Fleshing out this return occupies the rest of the Phenomenology.

Methodologically, the upshot of the introduction and its return to the phenomenal field is that concepts adequate to giving an account of ourselves and of scientific knowing must be responsible and adequate to what is revealed in the phenomenal field. But we must remember that the challenge the phenomenal field poses to inadequate scientific concepts of the knower and the knower's being also poses, for Merleau-Ponty, a challenge to inadequate philosophical concepts of the reflector - and thence to inadequate methodological conceptions of philosophy and phenomenology.

This challenge is of profound consequence for the Phenomenology. First and most obviously, it deepens the theme of radical reflection that is first broached in the preface and then haunts the rest of the Phenomenology, since the challenge tells us that our concept of philosophical reflection must be adequate to a phenomenal field that is pre-reflectively given. ${ }^{10}$ (Indeed, it should be noted that the phenomenal field chapter pursues issues of radical reflection through a dialectic between the opposite errors of a Bergsonian intuitive coincidence between knowing and being, and an infinite separation of knowing and being in doctrines of "universal constituting consciousness"- the very same dialectic that drives VI to "hyper-reflection."11) Second, rooting philosophy and reflection in a pre-reflective field of being anticipates deeper themes of the Phenomenology, for example, the pre-personal and perceptual learning and development, as leading to the result (in the "Sentir" chapter) that perception (and cognition) are rooted in an original past that has never been a present. Third, all of this leads to a key analysis of temporality that challenges any claim to a consciousness constituting temporality from 'outside' of temporality. What is instead required is a "passive synthesis" that operates only via openness to processes that we do not ourselves constitute. (PhP 488-89/489-91/426-28) ${ }^{12}$ This point about passive synthesis puts a final nail in the coffin of a reflective consciousness that would operate actively and in autonomy from its object. Philosophy has to wait for its object, wait to become philosophy-and passively wait to do this from within an already given phenomenal field.

What I want to emphasize, though, is that the issue of passivity (and waiting), to which the "Phenomenal Field" leads, in later chapters of the Phenomenology, is already there from the start, in the "Phenomenal Field" chapter itself. ${ }^{13}$ And attending to passivity and its methodological and ontological implications from the start can let us see how science can serve as a special resource in returning to the phenomenal field. So let us now turn to a key passage of the phenomenal field chapter — and, I dare say, of the Phenomenology and Merleau-Ponty's philosophy: 
Critical philosophy ultimately attaches no importance to this resistance of passivity, as if it were not necessary to become the transcendental subject in order to have the right to affirm it. It thus implies that the philosopher's thought is not subjugated to any situation. ... The center of philosophy is no longer an autonomous transcendental subjectivity, situated everywhere and nowhere, but is rather found in the perpetual beginning of reflection at that point when an individual life begins to reflect upon itself. Reflection is only truly reflection if it does not carry itself outside of itself, if it knows itself as reflection-upon-an-unreflected, and consequently as a change in the structure of existence. (PhP 74-5/89-90/61-2, last emphasis Merleau-Ponty's, initial emphasis mine.)

This passage is striking in that it exactly sets up the key issue of the passivity lectures (and thence the institution lectures), namely that "every theory of perception" runs up against the problem of accounting for the fact that the perceiver can make sense of what is given, yet the perceiver does not posit or constitute the given. Consequently, "the explication of perceptual experience must make us acquainted with a genus of being with regard to which the subject is not sovereign, without yet the subject being inserted in it [e.g., reduced to it]." ${ }^{14}$ This genus of being, which resists yet makes sense to the subject, is precisely what is at stake in passive synthesis in the Phenomenology's temporality chapter ${ }^{15}$ and even more in the "resistance of passivity" in the above passage. The problem with traditional conceptions of transcendental subjectivity is that they precisely forget that the "subject is not sovereign," that we become transcendental subjects; they thus erroneously imply "that the philosopher's thought is not subjugated to any situation"- that knowing is separate from being. In contrast, the phenomena lead Merleau-Ponty to conceive reflection as beginning at (and never completely escaping from) "that point when an individual life begins to reflect upon itself." ${ }^{\text {"16 }}$ Reflection is thus not truly reflection if it gets carried away with itself and "carries itself outside of itself," as if it could colonize all reality or subjugate it to reflective consciousness, as if philosophical reflection as such could already find itself operating as such outside of itself (as in a classic idealism, where ideas are carried outside of the subject), as if reflection did not rather depend on and arise out of its outside. Reflection must rather grasp itself as "reflection-upon-an-unreflected."

What's at stake in the Phenomenology's return to the phenomenal field is thus not merely finding the proper starting datum for phenomenology, but giving an account of phenomenology as an operation not merely of a reflective constituting consciousness, but of an unreflected to which it is passive. This is amplified in the sentences just prior to our passage, where he writes that reflection is not set up "in advance of the unreflected" but is rather a "creative operation that itself participates in the facticity of the unreflected," which is why, Merleau-Ponty says, "only phenomenology speaks of a transcendental field." Merleau-Ponty's emphasis on field here indicates that we are not speaking of a transcendental subject autonomous from facticity, but a subject given together with the field through which alone it operates, and to which, as the subsequent sentences make clear, the subject is passive. ( $P h P$ 74/88/61).

That is, what's innovative about phenomenology is that it takes the subject to be a function of a field..$^{17}$ Knowing and being are a joint operation of one field, and so too is reflection. Reflection is thus radically responsible to its roots in an unreflected, such that reflection does not itself fully accomplish itself, but hinges upon an unreflected that the subject cannot subjugate, through which alone a life can become reflective. Yet, this unreflected is precisely what enables and indeed motivates reflection. ${ }^{18}$ Radical reflection is thus peculiarly passive vis-à-vis its unreflected: if it lost the resistance of passivity, it would fall back into being a reflector, a constituting consciousness - and all the skeptical and dualistic worries of Structure would be revived. Hence Merleau-Ponty's motives for his later study of passivity, and his correlative interest in institution as a process that establishes new senses and meanings, not through 
constitution, but through enduring something that motivates sense even though this something does not yet fully make or determinately have a sense.

So far we've established that radical reflection operates in a phenomenal field wherein reflection is passive to an unreflected. But here a methodological complexity comes to the fore vis-à-vis conceptualizing radical reflection, namely that to do so we in turn need to conceptualize passivity with phenomenological rigour. How are we to do this? The problem is that we always encounter passivity as already mediated by our reflective activity and thus as already in principle subjugated to our reflective prejudices-which is why we tend to miss the "resistance of passivity” and end up prejudicially conceptualizing the subject as sovereign.

This methodological issue is behind Merleau-Ponty’s insistence, in the passivity lectures, that rigorous conception of passivity entails a new genus of being that is unfamiliar to traditional philosophies. Traditional philosophies end up trying to conceptualize passivity as, for example, a dearth or absence of activity, rather than a new genus of being in its own right, a genus with its own resistance (not just resistance to us or to activity). Passivity is its own, positive phenomenon. This is why he tries to approach passivity through phenomena like sleep and the unconsciousphenomena in which we are taken over by something that undoes our activity and active reflection, and does this undoing in its own terms. And yet, precisely because sleep and the unconscious undo reflective activity - and thence undo our ability to reflect on this undoing from within our own first person activity in the moment of their happening - to get at sleep or the unconscious as exemplary of passivity we need to do something like observe what goes on in others with regard to sleep or the unconscious, or wait whilst we go in and out of sleep, and then appeal to passively eruptive revenant memories of this going in and out of sleep. That is, to gain a phenomenological edge on passivity, we have to abandon our pretence to being wholly active reflectors dissociated from the phenomena, and instead realize that on a very deep level, what it is that we are trying to observe is something that we have to wait for and that carries us along in observing. We have to go passive and go outside our limits to encounter passivity. We have to wait for it.

Now this is what natural science is good at: in science you have to wait to observe what makes sense, rather than making up your own mind about what makes sense in a seemingly spontaneous and autonomous act of reflection. Indeed, we can think of rigorous science as a kind of responsible passivity. ${ }^{19}$ Whereas philosophical reflection could end up being responsible all and only to our own interior activity, science tries to be responsible to something that it itself cannot generate. Of course, in experimental manipulations, science sometimes tries to hurry things along, but the experimental control, for example, is meant to counterbalance this, to let the phenomenon intrude on us in its own, unhurried time. This is all to say that science is a way to gain an edge on passivity, to open ourselves up, in a rigorous way (that would still need conceptual critique) to what is going on in being and our being, prior to reflection.

Put another way, the phenomenal field names a pre-reflectively given domain in which reflection encounters phenomena that make sense, yet in such a way that what is given inherently emerges from and bears the legacy of operations beyond us, to which we are passive, even as we lend creativity to them, such that each phenomenon as it were says "I make sense to you, yet you did not fully constitute the sense that I make.” Vis-à-vis the phenomenal field, the problem with the traditional philosophy of reflection, which puts the reflector outside and above the field, is that it thinks the only sense there is comes from inside the reflector. The problem with traditional empiricist philosophy and traditional science is it says that there really is no sense. The issue of passivity indicates an integral hinging between the sense that I make and a sense that I cannot 
have made, between the reflection and the unreflected. My contention is that science is perfectly positioned to study this hinge point, and indeed, Merleau-Ponty's Phenomenology does study this hinge point through the science of the body. And yet, the science of Merleau-Ponty's time, that he analyzes, keeps on eschewing sense.

So, on the one hand, in the Phenomenology science does not succeed in returning us to the phenomenal field, since it fails to grasp that field as a field of sense and thence a field that is in and of itself (in advance of our reflective judgements and mental operations), phenomenal. And, on the other hand, if we were to stick with a criticism that Merleau-Ponty later makes of his own work $^{20}$, the Phenomenology's philosophy also does not ultimately succeed in returning us to the phenomenal field, since all it really does is convert a disembodied constituting consciousness into a lived-bodily constituting consciousness that generates the sense of things from within itself, without really running into the resistance of passivity in a phenomenal field beyond it. That is, all the Phenomenology really does is install the phenomenal field within the confines of the lived body as active constituter of sense and wholly active self-possession, versus installing the lived body inside a phenomenal field upon which and within which the lived body's sense making operations depend.

But this does not mean that science is of no use in returning to the phenomenal field, even if the science of Merleau-Ponty's time cannot let him effect this return. Let us not forget that the Phenomenology's return to the phenomenal field precisely starts out as a critique of scientific knowledge of the body, and this engagement with science shapes his return to the being of the lived body. Moreover, in pursuing this return Merleau-Ponty garbs the body with a fringe of habit and pre-personal operations, to which we are already passive. Further, by drawing on science, which approaches the body as a living system, he traces our lived body in relation to operations that we do not ourselves constitute, yet on which we depend and that sometimes erupt in our activity (as in sleep). By paying attention to that living fringe that erupts within experience, beyond the sense that we actively make, and showing how something more radical than the classic scientific conception would allow is at work there, we can step past the worry that the Phenomenology's phenomenal field is merely the emperor of constituting consciousness in new clothes. ${ }^{21}$ Indeed, above I argued that the methodological issue that connects radical reflection to passivity positions science as a possible resource for showing how (within the phenomenal field) reflective knowing is inflected by and through unreflective being. This of course means that unreflective being (the new genus of being that he is seeking in the passivity lectures) is in fact already implicitly on the way to reflection, via a "creative operation that itself participates in the facticity of the unreflected"-unreflective being can engender sense. And here it is worth noting that right from the preface the Phenomenology operates via a remarkable interlacing of science and phenomenology. While the Structure drives Merleau-Ponty to take up a Husserlian phenomenology, and as in Husserl, Merleau-Ponty's phenomenology begins as an effort to describe the unsurpassable foundations of science as rigorous knowledge, MerleauPonty's way of elucidating these foundations is very different: not simply through what philosophers say about science and scientists, but through what science says about science and scientists!

That is, right from the start science, scientific testimony, and the natural being that science studies, participate in Merleau-Ponty's phenomenology of the knower, as leading also to an ontology of a knower whose knowing is a function of a broader field. Science is thus a resource that Merleau-Ponty deploys in the Phenomenology as having a special role in returning to the phenomenal field — even if the Phenomenology might not fully succeed in this task. 
Finally, I think this methodological linkage that I have traced, from the phenomenal field, through passivity, to science as a resource for returning to the phenomenal field, is at stake in a remark that Merleau-Ponty himself makes in an introduction on science and philosophy in part two of his first lecture on nature:

How thus not to be interested in science in order to know what Nature is? If Nature is an allencompassing something [Englobant] we cannot think starting from concepts, let alone deductions, but we must rather think it starting from experience, and in particular, experience in its most regulated form-that is, science. $(L N 122 / 87)^{22}$

In his later texts, "nature” comes to designate being as phenomenon, as visible. Being, though, is more than just nature. Being includes its own endogenous invisible 'depths,' in virtue of which being has the latitude to engender the complex dynamic of nature as visible phenomenon, without nature being the manifestation of some essence behind the scenes, outside of nature, or even being a manifestation of abstract and already given universal laws, etc. (This ontological structure of manifestation is what's at stake in Barbaras's concept of phenomenality.) MerleauPonty is in part interested in nature because a proper reading of nature as visible being can effect a reading or diagnosis of the ontological structure of being, that is endogenous in being, as the invisible of visible nature. (Something like this is at stake in his notion of a "psychoanalysis of nature". ${ }^{23}$ ) In the passage above, though, Merleau-Ponty is reminding us that we are part of the very nature that we are trying to read, englobed by it. So our reading of nature is effected not through a reflective activity that spontaneously forges concepts and deductions from above nature, but by dint of nature itself. In other words, our reading of nature is passive to nature as a visible accessed through experience-even though our reading is also an activity. To read the ontology of nature we therefore need to plunge into experience. But the most rigorous way to do this is to plunge into experience in its most regulated form, which we find in science, wherein (I would say) responsible passivity exposes the sorts of moves that nature is already making of itself. This methodological point in the nature lectures is a reprise of the issue traced out above in terms of the phenomenal field, passivity, and science as a special resource for tracing the phenomenal field from within. But yet: science as 'producing' regulated experience tends to think it is doing the regulating, that it is ordering things, or that the ordering of things corresponds to ideal laws that make sense to us (or a divine mind)-versus a sense that arises out of nature itself, from below, a sense that we do not actively construct. ${ }^{24}$

Accordingly, what I am now going to do is show how more recent science can in fact help us get to the phenomenal field, as a field of operations beyond us, which engender its own sense, in advance of our reflection-by learning how to read life, via embryogenesis, as a phenomenal field that makes sense of itself.

\section{2) From Embryology and the Regulatory Genome, to Life as Phenomenal Field}

In his later lectures Merleau-Ponty himself turns to a study of embryogenesis to gain insights into the pre-personal genesis of sense in nature and being. ${ }^{25}$ By drawing on recent developmental biology, I want to show how we can advance this later project, but (for reasons discussed above) I do this in terms of the earlier concepts of structure and the phenomenal field.

I pursue this project through an extremely compressed discussion of biologist Eric Davidson's remarkable 2006 book The Regulatory Genome. Davidson synthesizes decades of

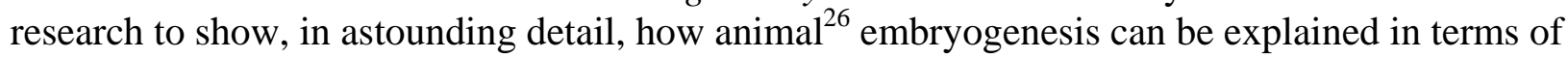
a “regulatory genome.” I begin with a synopsis of Davidson's result, gearing it to the claim I shall make about Davidson, starting on a large scale and then moving to finer grained detail. ${ }^{27} \mathrm{I}$ 
hasten to add that my aim is neither to dismiss nor belittle the truly astounding results achieved by Davidson (with a host of other scientists, technicians and computer programmers). However, scientific advances do not always accomplish the conceptual frameworks adequate to their findings. Philosophy can be an aid in sifting for such frameworks. And while I do not presume to have hit on a conceptual framework fully adequate to the findings, I nonetheless think there is something to be learnt from a critique of such concepts.

Simply put, scientists mainly and typically want to say that the genes are doing the regulating of embryological development. ${ }^{28}$ Drawing on Merleau-Ponty, I argue that organisms are doing this regulating as structures that are not reducible to genetic networks, even though crucially articulated by them. This will lead to the concept of life as a phenomenal field, for once we grasp genetic regulation as structural in character we will see that it has what Merleau-Ponty would call an expressive ontology.

As with prior embryologists, including Hans Driesch (who Merleau-Ponty studied), Davidson's central problem is explaining how one totipotent cell develops into a highly differentiated and species-typical animal body - and can do so in face of perturbations. Such development according to type, despite perturbations, is said to be regulatory. Davidson's basic claim is that regulation is achieved via a regulatory genome that amounts to a computer composed of hardwired genetic elements. ${ }^{29}$ The complex information processing capacity of this genomic computer is what explains development. Such processing, e.g., determines where, say, legs versus antennae are to grow. More, this processing capacity, as inherently flexible in responding to changing inputs, explains development's regulatory (robust) characteristic.

In Merleau-Ponteian terms, such processing generates sense, since it determines, e.g., that this organ is to be a leg, not an antenna, and that the leg is to go here, not there: it determines differences that make a difference to and within the material process of the organism, where these differences and the difference they make are thus inseparable from material processes. ${ }^{30}$ Further, as we shall see, this sense is determined according to standards themselves generated by the organism in the course of development (and evolution), rather than standards wholly fixed in advance of development.

My claim is that the regulatory genome ought not be conceptualized as a computer, a finite state automaton. Instead, its operation is central to what I call a self-articulating, selftransforming structure. This structure encompasses both the regulatory genome and the growing body in its environment. ${ }^{31}$ Think of Merleau-Ponty's account (in SB) of the soap bubble as a structure shaping itself through its overall dynamic in its environment. The developing organism is like this bubble structure, but the regulatory genome at its core gives it a dynamic and recursively complex responsiveness, that enables both the determinate articulacy of developmental responses, and the means to transform this articulacy, by movement that is (on both developmental and evolutionary time scales) open to an environment beyond the organism. $^{32}$

That is, the regulatory genome does not specify an already fixed, overall growth process, as if development merely reads out steps of a fixed plan. ${ }^{33}$ The frog egg doesn't grow directly into a frog, it first grows into a tadpole that only then can grow into a frog; the tadpole-body is ingredient in whatever we might call the 'frog-plan'. In this sense, development operates recursively, by transforming prior plans to develop new plans, where, crucially, the plans in question are not abstract information, but actual bodies of organisms.

In more detail, the regulatory genome is determinately responsive to: external signals; and internal genetic signals emitted by the regulatory genome itself, and transformed inside the 
organism via growth and further responses of the regulatory genome. In responding to signals, the regulatory genome can modulate either growth processes or the production of signals. And, most important, it can produce or respond to signals that modulate the way the regulatory genome itself responds to and does all the above. Recursive development thus depends on a recursive operation of the regulatory genome: like a recursive function that takes its own output as its input, ${ }^{34}$ the regulatory genome's output complexly depends on the different ways it works on itself, where this 'working on itself' is mediated by its real-time interactions with the environment. And these interactions are not merely information processing, but full-blown biochemical processes of and within the body whose bounds allow such processes to occur in the first place.

Put another way, the regulatory genome establishes and operates under what we might call different regimes of response, which themselves also mediate regime transitions. (Think of Socrates in the Republic showing how a regime, by its very own activity, determinately transitions into another sort of regime, e.g., oligarchy into democracy.) Computer scientists would call such 'information processing regimes' states. A finite state automaton, a classic computer, is a machine that responds to inputs in a manner determined by its current state-but in such a way that a possible response is switching into another state. The way the computer recursively acts on itself not only effects transitions between states, but modifies the way in which it transitions between states. (I.e., state transitions can also transition to new state transition tables.) This gives the computer its complex power.

We are now prepared for the central conceptual issue. While Davidson acknowledges that the regulatory genome differs from classic digital computers, he nonetheless conceptualizes it as a computer and thence conceptualizes it as kin to a finite state automaton. ${ }^{35}$ On my view, the regulatory genome is, however, radically different because its state transitions are not accomplished purely by the regulatory genome itself. Rather, the timing and orchestration of state transitions is mediated by the very growth that the regulatory genome itself orchestrates. Something outside the regulatory genome, namely the physics ${ }^{36}$ and biochemistry of the organism's environmentally embedded growth (as well as dynamics and genomics inherited from the organism's ancestors ${ }^{37}$ ), is thus internal to the genome's recursion upon itself and the orchestration of state transitions. Andy Clark and others ${ }^{38}$ argue that the mind extends into 'external' note pads on which we write things down, as Heidegger had already shown. My point is that the growing body itself serves as a crucial 'scratch pad' on which the regulatory genome 'writes down' its current state; more, the very growth that the genome regulates inherently transforms this 'scratch pad' in ways crucial to orchestrating the regulatory genome's operations. ${ }^{39}$ Indeed, even Davidson notes that if the regulatory genome is a computer, it is a massively distributed, parallel computer, with a copy in each cell of the growing organism. This is a computer that grows. ${ }^{40} \mathrm{I}$ add that this growth substantively modifies the very architecture of the 'computer,' in ways crucial to what it does.

Put in Merleau-Ponty's terms, development is not a matter of a central 'machine', the regulatory genome, responding to inputs from outside. Rather, it is the environmentally embedded self-transformation of one overall structure. This structure comprises the regulatory genome and the organism's growing body. This structure, though, differs from a soap bubble, in that its dynamic responsiveness is not a matter of a continuum of responses determined by mere physics. Rather, it enacts a restricted set of responses, those mediated by the regulatory network, ${ }^{41}$ and these responses are, moreover, determined by different growth regimes that themselves order one another. This is a highly articulate 'bubble', and we can think of its 
different growth regimes as together generating the organism's norm, to use Merleau-Ponty's term. Indeed, the regulatory genome's establishing and switching of states enables what the geneticist Theodosius Dobzhansky called a norm of reaction, a highly complex way of at once reacting to the developmental environment whilst maintaining a norm in face of perturbation.

This structural articulacy leads me to my concept of a self-articulating/transforming structure. The developing organism is not a mere machine, with parts operating outside of parts, it is a structure in the Merleau-Ponteian sense. Nonetheless, in virtue of the regulatory genome's operation, this structure is internally, complexly, dynamically, and recursively articulate. This articulacy is key to developmental regulation, and exceeds any fixed set of finite states, since the articulacy in question can re-articulate itself, producing a new set of finite states, or giving these states new, living meaning. Thus my concept of a self-articulating/transforming structure, wherein the self-articulation of the structure can lead to its transformation into a new articulatory structure, and self-transformation proceeds through new ways of articulating the system, such that the engendering of sense is always passive to yet transformative of material processes and articulatory legacies. That is, what we have here is a system that we could never think of as autonomously constituting its sense, since sense production is always a labour that operates through inherited legacies that at the same time enable new senses to develop. To get at this difficult point, which would be hard to fully unpack here, let me turn to Husserlian concepts: the regulatory genome determines something kin to a horizon structure of articulate potentialities; but this horizon structure is internally complex, and recursively modifies itself, switching in new sub-horizonal structures. ${ }^{42}$ Yet, how this switching actually proceeds is precisely not fully determined inside the horizon itself. It is open to an outside (to material and energy flows) and to time- - but not the time of subjectivity, rather a time going back to the material and dynamics of the parent organism, to the species-time of evolution, and to prior plan-bodies (e.g., the tadpolebody) that orchestrate development. Note that this notion of horizon structures susceptible of recursive modification through exposure to time and outside inputs, gives a pre-cursor of the delicate balancing act that Merleau-Ponty traced with regard to reflection as arising "at that point when an individual life beings to reflect upon itself," since the point is that self-articulation and transformation is always passive to an outside.

Indeed, what we have here is something of an anticipation of a central point of the Phenomenology's temporality chapter, which argues that the synthesis of temporality operates only as passive to the very flow that it synthesizes. We are seeing that development is not a genetic program in control of unfolding itself, but instead is open and passive to already-given plan-bodies and environments that enable and orchestrate the genetically regulated flows through which growth occurs and the body literally synthesizes itself. ${ }^{43}$ So, given that philosophical reflection is accomplished in lived bodies that are born and develop, what we are getting here is powerful testimony, from outside of reflective experience, that reflection is engendered out of a passivity that goes deep into life and nature. Indeed, we could put the above in terms of MerleauPonty's key image of passivity, sleep: frog development, as needing to inherit the tadpole-body as plan and legacy, involves something kin to the frog-as-growth-agent going to sleep, passively handing itself over to the tadpole-body, to wake up only when the tadpole-body has finished its growth, and started 'growing froggy'. This image, though, artificial divides tadpole growth and frog growth - but just as much as our discussion of sleep artificially divides the sleeper from the one awake. It is only because the two are mixed yet immiscible that one can wake or be called to wake from sleep. 
But let us return to more basic issues that further highlight a passivity and, more important, an expressivity endogenous to sense-generation. It follows from the above that the sense generated in development by the self-articulating/transforming structure is not already contained, even in implicitly determinate form, in the fertilized egg. The egg is what can generate the sense of the adult organism, can make sense of itself, but it cannot do this from within itself, autonomously. Whatever determinate indeterminacy the regulatory genome has, this does not yet suffice to engender the organism. This engendering requires factors beyond the genome, most of all the growing body as organizing, orchestrating and 'drawing out' this determinate indeterminacy. And this engendering can happen in different ways, even if tending to the species typical.

This means, though, that growth is a process that exhibits the peculiar logic of expression so central to Merleau-Ponty. In this logic, the result of expression is not yet determinately contained as such in the beginning of the expressive process, since the result does not resemble this beginning. Yet, on the other hand, the result is not independent of what was there in the beginning. Sense is engendered, but not by unpacking a pre-formed sense. As Merleau-Ponty would put it, in cases of what he calls primary, creative, (human) expression, I do not know what I want to say until I figure out how to express it. What I want to express is thus not yet there at the beginning of expression; nonetheless, when I do figure out what I want to say, I realize this was what I wanted to express all along. ${ }^{44}$ Husserl's horizons are once again helpful: it is precisely because the horizon of primary expression is open and indeterminate that it can yield a creative sense, an X that I did not yet know how to say; yet, this indeterminacy is a determinate indeterminacy, since it is precisely this determinate $\mathrm{X}$ that I did not yet know how to say.

As Bernhard Waldenfels notes (2000), for Merleau-Ponty primary expression is thus a peculiar kind of translation that creates the original text that it translates. We can see this in the regulatory genome: it operates in such a way that it produces the transcription products that serve as signals that sequence state transitions; the regulatory genome's 'task' is thus not to unfold a pre-formed plan, but to, in the first place, continually produce, in situ, the 'plan' that can then be translated into the adult animal (for example, the tadpole-body as crucial to the growing organism translating itself into the 'frog-plan'). To put it in terms closer to Davidson, he points out that the regulatory genome differs from ordinary computers since there is no real division between hardware and software; the regulatory genome's operation is such that it is always 'reprogramming' itself. The genome is thus translated (its 'programming' turns 'hardwired code' into actual genetic signals) in such a way that this very translation creates, via modulation, the original text (the programming, orchestrating signals and context) that ends up being translated. Although we can conceptualize the frog genome as already 'containing the genetic text' for a frog-body, this is not the way things actually work. It is only by way of the frog-egg (in its environment) translating itself, via its genetic material, into a tadpole-body that this 'original genetic text' actually becomes translatable into a frog-body. Or better, since we would have to 'fractally' interpolate a host of smaller versions of this point, we find that the 'translation' is inseparable from the very growth of what it is that does the translating. The 'text' is not already there, except in a sort of 'ur-text' whose translation in fact re-splices and differently transcribes it, to produce the 'text' in the first place, in a complexly dynamic recursive process, that is, moreover, modulated by the dynamics of bodily growth. Hence the expressive characteristic of this process: it is kin to a process in which someone says something not by already being able to say it, but only by becoming the practitioner of language who is then able to say it. In so far as the developmental plasticity endogenous to such processes plays out as typical, we have 
something kin to secondary expression; insofar as such plasticity inherently enables deviation from the typical, and inherently enables cleavage to type through atypical routes, either on the individual or evolutionary timescales, we have something kin to primary expression.

Put another way, Leonard Lawlor $(1998,22)$ observes that Merleau-Ponty's paradox of expression is kin to Deleuze's, in that the " ‘the expressed' does not exist outside of the expression and yet bears no resemblance to it.” Here we can observe something striking: organismic development perfectly captures this paradoxical logic. The adult organism does not really resemble the egg from which it grows, yet the adult clearly does not exist outside or independent of the egg or its growth. The adult is the egg become different, yet this becoming different, we are now seeing, is not by way of resemblance, not even an invisible resemblance, since the adult organism is not the unpacking of a pre-formed plan, but rather the generation of a plan on site, through time.

On the basis of this analysis, we can see that a self-articulating/transforming structure is expressive. Whereas a soap bubble is always going to resemble itself in its response to the environment, because its structure is invariant, in organisms we have a virtual norm that is not given as such at the beginning, but becomes express.

At this point I want to dip into a bit more detail about how the regulatory genome actually works. Davidson shows how we can conceptualize the animal's DNA as containing, amongst other things, regulatory modules. Each such module has sites that, when transcribed, produce genetic signals or components of the organism. But the modules also have other sites where genetic signals can attach. These attachments can modulate production of signals, and thence modulate other sites, via intermediary genetic signals. Each module can be conceptualized as a set of logic gates, some scalar, some binary. Significantly, these gates can work in a combinatory way, and modules combine in networks. For example, $\mathrm{C}$ outputs a signal only if signals $a$ and $b$ are both present, with C's output being suppressed by $\mathrm{E}$ if $d$ is present. Indeed, the logic of these modular networks can be represented in the form of a computer program.

These details are worth mentioning because, in a way, Davidson perhaps suggests a solution to a problem that Merleau-Ponty addressed in his studies of embryology in the nature and institution lectures. There, as always, Merleau-Ponty was looking for a way to the phenomena and to sense, between empiricism and idealism, materialism and idealism. Specifically, his critical analysis, which I cannot rehearse here, led him to seek a way to account for the regulatory character of embryos, which Driesch had discovered, but without succumbing to Driesch's vitalist appeal to an immaterial, “metaspatial” “entelechy,” or to a materialist account that would somehow reduce the organism's plan into atomized bits, or a spatial ensemble thereof. Merleau-Ponty's analysis turns on a dialectic between the metaspatial and spatial, which leads Merleau-Ponty to something "transpatial," which he hints at in the institution lectures in terms of "triggers of "reaction," "signals": transspatial feedbacks" (IP 50/17) and in the nature lectures in terms of a "gap," a negative in being, "encrusted between the [material] situation and the [developmental] response"-but where the transspatial cannot be located as something given in space. ( $L N 301 / 237$ ) This is what I think Davidson is showing us: he is showing us how the material configuration of the regulatory genome is key to development, but (on my argument) not as something given here and now, spatially. The regulatory genome has this role only as part of a temporally and spatially open, distributed feedback structure that is yetto-be, via a kind of organismic différance. The regulatory genome only makes sense, a difference that makes a difference, when it repeats/recurs upon itself through differing and deferring from itself. What is interesting is that Davidson lets us see this 'différance potential' in a distribution 
of molecules in a system. On the one hand, this gives us a way into grasping life as an exposure to passivity that can yet make sense, life as making sense through a sort of undoing of the concept of already given sense - which is at stake in Merleau-Ponty's notions of passive synthesis, temporality, and institution. On the other hand, the temptation in science (and this is Davidson's temptation) is to reduce this possibility of living sense-making to the informational content of the genome, in which case, vis-à-vis the larger questions at stake here, we'd end up with an informational/computationalist version of constituting consciousness, and lose the passivity that is at issue in the phenomenal field and Merleau-Ponty's later ontology.

Indeed, at this juncture we can precisely see the need for Merleau-Ponty's ontological investigations, for while, as promised above, we can here see how engaging science methodologically enables a challenge to our all too active position as knowing reflectors, by showing how our bodily, evolved, developmental roots in being expose us to radical contingencies and temporality, we are in fact at a point where we are, in a way, repeating, albeit on a micro-scale, the problem at the hinge between Structure and the Phenomenology, namely whether the above reading is merely projecting reflective issues of structure, expression, etc. on to organisms. To head off this worry would require a demonstration that nature and living processes themselves can bear the ontological burden with which we have here saddled them. There is not enough room for this here, although I have a way to it that complements some issues about negativity, depth and genesis in the later Merleau-Ponty. ${ }^{45}$

What is important, though, is that the sort of analysis given above gives finer grained definition to the problem, and a way into it through science that can temper the methodological dangers of conceptual 'activism', by having science, through its cultivation of the responsible passivity of observation, draw attention to the ways in which nature has to wait to be nature. Embryogenesis is not regulation wholly and fully actively under control by an inner genetic essence or regulatory computer, it turns on passivity. The frog cannot jump from being an egg into being a frog, without waiting for all the phases and moves between, which take time, exposure, openness - which is why rate and thence temperature and chemical inputs are so important in biological development. A computer program will play out exactly the same no matter how fast you run it (given inputs that can keep up), but if you speed up or slow down living growth you can get something different. The difference between sexes in alligators depends on temperature of egg incubation, not genes; the queen bee's phenotype is determined not by inner genes merely, but by the royal jelly playing on these genes through the ingesting body.

Development is in this respect passive synthesis made flesh. It is an active operation that yet turns on something beyond itself to which it is passive. In this way, a science of development can give us an insight into how a phenomenal field can arise wherein passivity to something not yet organized (and thus resistant to reflective analysis) can turn into something organized (amenable to reflective analysis and even capable of reflection). Indeed, such science shows how in the case of life the organized necessarily turns to and out of the as yet unorganized. ${ }^{46}$ It thus shows us something about the deep phenomenology and ontology of the hinge between reflection and the unreflected, which hinge is at stake in radical reflection and hyper-reflection, at the "point when an individual life begins to reflect upon itself," without yet being sovereign vis-à-vis what it reflects upon. Methodologically, it crucially shows us this not from within our own active reflection, but in the pre-reflective movements of life-through a responsible passivity to nature. 
This result is relevant to Merleau-Ponty's later philosophy, for it suggests how we could look to development for clues to the ontology of the visible and the invisible. For what we have observed is that organisms, in their development, do not reflect invisible 'essences', but rather what Merleau-Ponty would call the invisible of the visible, via what Barbaras designates phenomenality (see above). And we can now glean how this invisible is right there within the visible: it is not an essence, it is rather an invisible of generativity, what I called above a 'différance potential'. This sort of generativity is invisible in that it has not yet fallen into a specific, determinate visibility — or even a determinate, visible potentiality. It is not yet determinately visible because the generativity as stake here is inherently mutable-because inherently passive. In fact its mutability is the mutability of temporality, and its invisibility is the invisibility of temporality (which is what Merleau-Ponty was opening up in the

Phenomenology's study of temporality). But the case of development would show us how this invisibility of temporality shows up, as paradoxically invisible right there in the visible, only when temporality makes a difference in, is passive to, a material system - and this will require boundaries and place, a kind of space-like complement to temporal passivity. But this is a topic for another paper.

So let me conclude by returning to the phenomenal field. For what has been shown above is that life exhibits a sense that is engendered within a field, out of something that does not yet already contain the sense that will be engendered, yet without which sense could not have been engendered. (The egg doesn't already contain the sense of the frog, but without the egg, no frog.) Since we ourselves are living, and thus grow and develop, it is empirically and unsurpassably the case that our experience arises within such a life-field of sense. Indeed we can see that legacies of this sense generation, legacies of our living growth and development, concretely inform the world of sense in which we live (without yet fully determining the sense of our world, as this sense is taken up in individual, cultural and historical institutions). In this respect the field of life is an unsurpassable and transcendental field from which phenomenological reflection begins. Life is the first and deepest form of the phenomenal field, the oldest institution of sense. ${ }^{47}$ And philosophical reflection, as unsurpassably arising from and within life as phenomenal field, thus entails a radical- or hyper- reflection that is (passively) responsible to its roots in life as phenomenal field, a hyper-reflection that traces how it is that philosophy arises out of 'older' operations. But this would demand of us a new ontology that can find sense in the flesh of nature. The thought here is that we can begin reading this new ontology through development.

${ }^{1}$ I would like to thank Shiloh Whitney, Noah Moss Brender, Donald Beith, Lisa Guenther, Tristana Martin Rubio and Don Landes for their invaluable contributions to my understanding of Merleau-Ponty on institution, passivity and nature. I also thank Dan Landreville for further insights on passivity and discussions of the relations between the passivity lectures and the Phenomenology. I would especially like to acknowledge Noah Moss Brender's crucial, critical and editorial comments on an initial draft of this paper, and acknowledge his careful work on organisms and Merleau-Ponty as of continual interest and inspiration.

${ }^{2}$ Merleau-Ponty's works are cited by the abbreviations indicated in the text, followed by page numbers in the French and then English editions. The exception is $P h P$, which is cited by page in the original, pre-2008, Gallimard edition; then page in the 2008 Gallimard; then page in the original English, pre-2002, edition. The translation of $P h P$ quoted here is the 2012 translation by Donald A. Landes, which includes the 2008 Gallimard pagination in the margins. 
${ }^{3}$ Saint Aubert (2006), chapter III, §4 gives a helpful textual analysis of some of the places where Merleau-Ponty himself avows points about philosophy's relation to science. My effort here is more to discuss Merleau-Ponty's relation to science by tracing and reconstructing how he actually positions science in relation to his method and the workings of his philosophy —and also to discuss what he could have done. For some other studies of issues around Merleau-Ponty and science that are helpful background, see Toadvine (1999), De Beistegui (2005), Holland (2002), Robert (2006).

${ }^{4}$ E.g., Toadvine (2008) gives a nice summary of the methodological issue that is of interest here, namely the way in which Merleau-Ponty's phenomenology turns, through radical reflection, into his later "hyper-reflection.” But this is mostly worked out through PhP's preface, missing stronger anticipations of $V I$ and hyper-reflection in the phenomenal field concept. Similarly, the issue at hand is implicit in the astute reflections on phenomenological beginnings in Sallis (1973), but there too the phenomenal field is bypassed. Lawlor (1998), on the other hand, does notice something quite radical in the notion of the phenomenal field. Although its centrality is not treated directly, the phenomenal field figures in the study of expression in Kristensen (2010) in a way that flags some of the issues discussed below.

${ }^{5}$ The methodological worry that our philosophical activity, as all too constitutive of its object, might throw phenomenology off track hovers over IP, this paper, and Merleau-Ponty's project in general. For helpful papers on this topic, see Heinamaa (1999), (2002). Also see Morris (2005). For a different approach to this sort of issue in Merleau-Ponty see Alloa (2008).

${ }^{6}$ Note that an activity of reflection is, however, requisite to explicitly exposing the significance of these revelatory operations for phenomenology. The issue flagged here, about the relation between phenomenology and life, and the notion of phenomenality — of phenomena not as the showing of something else, but rather as being's show of itself through a distance within itself that is exemplified by living movement and desire-are central to Barbaras's work, which is constantly in the background of the thinking in this paper.

${ }^{7}$ For discussion of sense and expression in Merleau-Ponty, see, e.g., Hass (1999), (2008), Lawlor (1998), Kristensen (2010) and Morris (2004), (2011).

${ }^{8}$ SB 223/206. The full formula specifies that structure is the "joining of an idea and existence that are indiscernible, the contingent arrangement by which the materials placed before us begin to have a sense, intelligibility in the nascent state." Again, compare this to the issues at stake in the phenomenal field as reflection-upon-an-unreflected and the linkages between structure and phenomenal field cited in note 16. This suggests that in some sense the phenomenal field concept is a phenomenologically transformed version of the structure concept, which point does not go unnoticed, e.g., in Tiemersma (1987). This would suggest a closer proximity between Structure and Phenomenology than Barbaras would allow (see next note).

9 The issue of where structure is ontologically 'located' haunts $S B$ and is at stake in its concluding chapter; it shapes Merleau-Ponty's appropriation of Husserl's phenomenological method in $P h P$. There is controversy, though, especially prominent in the work of Barbaras, whether the $P h P$ then betrays the project of $S B$, namely finding sense at work in observable life around us. I am precisely trying to show that on the contrary, $P h P$ maintains this issue, and could have recuperated it through an engagement with science. It's just that the science at MerleauPonty's time wasn't enough to let him make this move. 
${ }^{10}$ For key passages on radical reflection, see $P h P$ ix/14/xv; 253-6/263-7/219-222; and 45961/456-59/398-400. The latter gives a formula for radical reflection that links it to temporal thickness and thence passivity, since the analysis ends with the question how "subjectivity can be simultaneously dependent and indeclinable," i.e., inserted, as per below, in a phenomenal field.

${ }^{11}$ This dialectic becomes especially clear in the opening sentences of "The Intertwining-The Chiasm" chapter, which helps emphasize that the chapters on "Interrogation and Dialectic" and "Interrogation and Intuition" function as a dialectic that points out the shared error of Sartre's negative consciousness as reflective on and infinitely distant from its object, and Bergson's intuitive consciousness as coincident with its object.

${ }^{12}$ These passages on passive synthesis must be compared with the passages on the resistance of passivity cited below from the phenomenal field chapter, for in discussing passive synthesis Merleau-Ponty writes that "What we call passivity is not our reception of an external reality or of the causal action of the outside upon us: it is being encompassed, a situated being — prior to which we do not exist-that we perpetually start over and that is constitutive of us. ... [W] are entirely active and entirely passive because we are the sudden upsurge of time." (On this "being encompassed", cf. the Englobant in the passage from $L N$, on science as regulated form of experience, discussed below.)

${ }^{13}$ I would especially like to thank Dan Landreville for her insights about passivity and the relation between $P h P$ and IP in our various discussions of this topic, in particular for emphasizing the importance of passivity in the phenomenal field chapter.

${ }^{14}$ I am here quoting from Merleau-Ponty's course summary of the passivity lectures, IP 267/206.

${ }^{15}$ See note 12 .

${ }^{16}$ The language and thinking here are strikingly similar to the passage in $S B(175 / 162)$ where Merleau-Ponty, thinking about Hegel's philosophy of nature through Hyppolite, speaks of life and thence the concept as arising only "when a piece of extension, by the disposition of its movements and by the allusion that each movement makes to all the others, turned back upon itself and began to express something, to manifest an interior being externally.” This passage is worth citing not only because it anticipates issues of expression as an interior operative only through its exterior, which issues are key to the concept of the phenomenal field, but because the sort of logic of life at stake here is precisely what the study of embryology lets us trace in more detail.

${ }^{17}$ This issue is explored in various ways in Tiemersma (1987), but the focus there is on MerleauPonty's relation to the notion of field in scientific domains such as Gestalt psychology, vs. the larger philosophical significance of this term for Merleau-Ponty's philosophy.

${ }^{18}$ This is why, close to the above passage, Merleau-Ponty says that phenomenology always ends up being a "phenomenology of phenomenology," i.e., a study of how phenomenology arises, as a reflective project, in this field.

${ }^{19}$ This formula obviously brings phenomenology as science of experience, and natural science, into very close proximity. But developing this point would require another paper. 
${ }^{20}$ See, e.g., the famous "Dualism—Philosophy” note of July 1959 in VI, which many take as decisive. But see, e.g., Hass (2008) and the introduction to Toadvine (2009) for representatives of a 'continuity view' of Merleau-Ponty.

${ }^{21}$ A further question is whether some sort of engagement with a science of the living is necessary to resolving the problem of passivity; behind this is Barbaras's challenging shift of phenomenology from classical subjective to living phenomena; part of what I want to suggest is that this shift is already at stake in and achievable by Merleau-Ponty's engagement with science.

${ }^{22}$ My thanks to Noah Moss Brender for drawing this passage to my attention as complementary to points worked out in the initial draft.

${ }^{23}$ See the November 1960 note on nature in VI.

24 This is a problem I tried to trace in a different way through a study of abduction in Morris (2005).

${ }^{25}$ Indeed, this paper would not have been possible without Merleau-Ponty's studies of embryology and development, which, remarkably, show how development is in fact central to understanding the concepts of structure and totality as (in turn) central to the "idea of nature and maybe the whole of philosophy." ( $L N$ 194/145) These studies of embryology are to be found in: LN, 187-203/139-152, 293-308/230-242; and IP 16-7/49-50. Basically put, Merleau-Ponty is showing how we ought study embryogenesis if we are concerned to rigorously formulate notions of development and sense genesis that are adequate to the phenomena, and show how this requires a new sort of ontology. Note that Merleau-Ponty's studies of behaviour and behavioural development in the child may have contributed to his interest in embryology, since, e.g., Gesell (1971) argues that the development of cognitive behaviour and the development of the body are not two different things, which is also a theme central to Coghill's work, and we know that both Coghill and Gesell are important to $L N$.

${ }^{26}$ Davidson's focus is on bilateran animals.

${ }^{27}$ I have developed a detailed defense of the account below for another venue, but there is not enough room to do that here on this occasion. Leaving out the detail is troubling, for what is important and wondrous - perhaps Nobel-worthy_in Davidson's account is the detail. On the other hand, I have not in any case, been able to master these details. Such mastery would take years of study and familiarity with a plethora of genes, developmental systems and so on.

The discussion below is based on Davidson (2006), (2001), Istrail and Davidson (2005), Istrail, De-Leon and Davidson (2007), Yuh, Bolourie and Davidson (1998).

${ }^{28}$ But see, e.g., Fox Keller (2002), (2000a), (1995), (2005), Amundson (2005), and Wilson (2005) as examples of various philosophical challenges to the gene-centric or selfish-gene view.

${ }^{29}$ As Davidson puts it, a regulatory DNA sequence (the regulatory genome is composed of a multiplicity of such sequences) "amounts essentially to a hardwired biological computational device.” (Davidson (2006), 48) He is here speaking of the sequence that regulates transcription of the endo16 gene in the sea urchin. But he holds this sort of view in general of the regulatory genome. He writes of the genome as "a vast delocalized computer" (188); of evolution as "assembling endless varieties of the [genomic] computer" (240, with the "endless varieties" here perhaps being a nod to the famous closing passage of Darwin's Origin); and a key point, is that 
"the operation of the regulatory system can be symbolized, as in a computer program, by a series of conditional logic statements” (54), although in both (2006), Istrail and Davidson (2005), and Istrail, De-Leon and Davidson (2007) it becomes clear that the processing operation of this computer is different than that of an digital computer. What I am emphasizing is that this modular operation in fact depends, for its information processing efficacy, on a complex relation with its environment, which is the internal milieu of the growing body. See Fox Keller (2000b) for other critical reflections on Davidson's conception of the regulatory genome as actually being an (analogue) computer, not just something that we can model as an analogue computer.

30 The issue of leg placement is one of the issues that troubles Merleau-Ponty in $I P$, via his engagement with Ruyer.

${ }^{31}$ On the importance of the environment to development, see Weele (1999), Kirschner and Gerhart (2005), Wilson (2005).

${ }^{32}$ In speaking of response we would here run into questions of imputing agency, and so on; I here merely wish to use "response" to indicate that the products of genetic transcription are dependent on the presence of specific genetic products (and their modifications) in the cellular milieu. But see Wilson (2005) for reasons why we should be thinking about agency here.

${ }^{33}$ Cf. the point in Kirschner and Gerhart that what evolves in evolution are not so much organisms or blue prints for organisms, but ways of making organisms; correlatively, what the genome specifies are ways of making organisms, and nothing is fully specified by such specifications absent the making. This point that evolution reconfigures relations between conserved processes of organism construction (rather than coming up with new or modified 'blueprints') is what gives evolution its efficacy in constructing viable organisms. Again, we might think here of the logic of determinately indeterminate horizons in Husserl.

${ }^{34}$ An example of such a recursive function is to be found in the following specification of the factorial function: $0 !=1 ; n !=n *(n-1)$ ! Given this definition, we calculate 2 ! as a function of 1 !, which is in turn a function of 0 ! There is a sort of internal nesting and sequencing of functions, like the egg 'in' the tadpole 'in' the frog.

${ }^{35}$ Istrail, De-Leon and Davidson (2007).

${ }^{36}$ For this point about the physics of growth mattering insofar as adhesional forces, diffusion patterns, etc., organize growth (and thence would mediate the distribution of genetic signals), see Goodwin (2001) and Forgács and Newman (2005).

${ }^{37}$ Jablonka and Lamb (2005).

${ }^{38}$ See Clark (1997), (2008), Clark and Chalmers (1998).

${ }^{39} \mathrm{Cf}$. the analogy that Wilson (2005) makes between externalist views of mind and his own critique of gene-centric views; I came across this after drawing my own analogy.

${ }^{40}$ See Istrail, De-Leon and Davidson (2007).

${ }^{41}$ One might want to say here that the set of responses is strictly finite, but this would already presume an information processing view of the regulatory network, that abstracts from its physics that renders signals inherently plastic, and in any case we must remember that the set of 
possible responses depends on maintenance of the organisms boundaries and internal transcription apparatus, etc.

42 See esp. Husserl ([1931] 1991), §19.

${ }^{43}$ In this issue of openness and the phenomenal field, we are in effect seeing a new version of the problem of the Kantian imagination as requisite to bringing concepts and intuitions together in experience. On this connection see Morris (2008).

44 See “The Body as Expression, and Speech" and Waldenfels (2000), Kristensen (2010) and Hass (2008) for helpful discussions.

${ }^{45}$ Around all of these issues, it is worth noting the explorations of a working note in $V I$ ("Labyrinth of Ontology," September 17, 1958) where he writes of the universe of meaning as repeating the universe of structure, and links these issues to question about a new concept of possibility that he explores by looking to salamander development for a clue to a new way to conceptualize possibility.

${ }^{46}$ But note that living beings in fact organize their surrounding environments, in ways that can be crucial to their physiological process, c.f., e.g. Turner (2000), Odling-Smee, Laland and Feldman (2003), Baluška, Mancuso, Volkmann and Barlow (2004).

${ }^{47}$ One could object that a transcendental field could not be subject to empirical contingencies such as those of biology. But this would forget that when Husserl, especially in the Cartesian Meditations, pursues the transcendental field, he does not set out in advance for a transcendental constituting consciousness above the empirical fray, rather he precisely opens himself to the field of experience as empirically given, and this is what subsequently leads him to identify the transcendental ego as unsurpassable - and fully tracing this ego leads him to the monad, the Leib, the alter ego, and passive syntheses and a genetic phenomenology.

\section{References}

Alloa, Emmanuel. 2008. La résistance du sensible: Merleau-Ponty critique de la transparence. Paris: Editions Kimé.

Amundson, Ron. 2005. The Changing Role of the Embryo in Evolutionary Thought: Roots of Evo-Devo. Cambridge: Cambridge University Press.

Baluška, František, Stefano Mancuso, Dieter Volkmann, and Peter Barlow. 2004. Root Apices as Plant Command Centres: The Unique 'Brain-Like' Status of the Root Apex Transition Zone. Biologia 59 (Suppl. 13):7-19.

Clark, Andy. 1997. Being There: Putting Brain, Body, and World Together Again. Cambridge, Mass.: Bradford Books/ MIT Press.

- 2008. Supersizing the Mind: Embodiment, Action, and Cognitive Extension. Oxford: Oxford University Press.

Clark, Andy, and David J. Chalmers. 1998. The Extended Mind. Analysis 58:7-19.

Davidson, Eric H. 2001. Genomic Regulatory Systems: Development and Evolution. San Diego: Academic Press. 2006. The Regulatory Genome: Gene Regulatory Networks in Development and Evolution. Burlington, MA: Academic Press. 
De Beistegui, Miguel. 2005. Science and Ontology: From Merleau-Ponty's "Reduction" to Simondon's "Transduction". Angelaki 10:109-122.

Forgács, Gabor, and Stuart Newman. 2005. Biological Physics of the Developing Embryo. Cambridge, UK ; New York: Cambridge University Press.

Fox Keller, Evelyn. 1995. Refiguring Life: Metaphors of Twentieth-Century Biology. New York: Columbia University Press.

—. 2000a. The Century of the Gene. Cambridge, Mass.: Harvard University Press.

- 2000b. Models Of and Models For: Theory and Practice in Contemporary Biology. Philosophy of Science 67 (Proceedings):S72-S86.

- 2002. Making Sense of Life: Explaining Biological Development with Models, Metaphors and Machines. Cambridge, Mass.: Harvard University Press.

— 2005. The Century Beyond the Gene. Journal of Biosciences 30 (1):3-10.

Gesell, Arnold. 1971. The Embryology of Behavior: The Beginnings of the Human Mind. Westport, Conn.: Greenwood Press.

Goodwin, Brian. 2001. How the Leopard Changed Its Spots: The Evolution of Complexity. Princeton: Princeton University Press.

Hass, Lawrence. 1999. Sense and Alterity: Rereading Merleau-Ponty's Reversbility Thesis. In Merleau-Ponty, Interiority and Exteriority, Psychic Life and the World, edited by D. Olkowski and J. Morley. Albany: State University of New York Press.

—. 2008. Merleau-Ponty's Philosophy. Bloomington: Indiana University Press.

Heinamaa, Sara. 1999. Merleau-Ponty's Modification of Phenomenology: Cognition, Passion and Philosophy. Synthese 118:49-68.

—. 2002. From Decisions to Passions: Merleau-Ponty's Interpretation of Husserl's Reduction. In Merleau-Ponty's Reading of Husserl, edited by T. Toadvine. Dordrecht: Kluwer.

Holland, Nancy J. 2002. "With One Headlight": Merleau-Ponty and the Philosophy of Science. Philosophy Today SPEP Supplement:28-33.

Husserl, Edmund. 1991. Cartesian Meditations. Translated by D. Cairns. Dordrecht: Kluwer. Original edition, 1931.

Istrail, Sorin, and Eric H. Davidson. 2005. Logic functions of the genomic cis-regulatory code. Proceedings of the National Academy of Sciences 102:4954-4959.

Istrail, Sorin, Smadar Ben-Tabou De-Leon, and Eric H. Davidson. 2007. The Regulatory Genome and the Computer. Developmental Biology 310 (2):187-195.

Jablonka, Eva, and Marion J. Lamb. 2005. Evolution in Four Dimensions: Genetic, Epigenetic, Behavioral, and Symbolic Variation in the History of Life, Life and mind. Cambridge, Mass.: MIT Press.

Kirschner, Marc W., and John C. Gerhart. 2005. The Plausibility of Life: Resolving Darwin's Dilemma. New Haven: Yale University Press.

Kristensen, Stefan. 2010. Parole et subjectivité: Merleau-Ponty et la phénoménologie de l'expression. Hildesheim: Georg Olms Verlag.

Lawlor, Leonard. 1998. The End of Phenomenology: Expressionism in Deleuze and MerleauPonty. Continental Philosophy Review 31:15-34.

Merleau-Ponty, Maurice. 1942. La structure du comportement. Paris: Quadrige/Presses Universitaires de France.

. 1945. Phénoménologie de la perception. Paris: Gallimard. 
- 1962. Phenomenology of Perception. Translated by C. Smith. Atlantic Highlands, New Jersey: The Humanities Press. Original edition, 1945.

. 1964. Le visible et l'invisible. Paris: Gallimard.

- 1965. The Structure of Behaviour. Translated by A. L. Fisher. London: Methuen. Original edition, 1941.

- 1968. The Visible and the Invisible. Translated by A. Lingis. Evanston, IL:

Northwestern University Press. Original edition, 1964.

- 1995. La nature: notes, cours du Collége de France. Paris: Seuil.

—. 2001. Psychologie et pédagogie de l'enfant: Cours de Sorbonne 1949-52.

- 2002. Phenomenology of Perception. Translated by C. Smith. London: Routledge.

—. 2003. L'institution/ la passivité: Notes de cours au Collège de France (1954-1955).

Paris: Editions Belin.

- 2003. Nature: Course Notes from the Collége de France. Translated by R. Vallier. Evanston, IL: Northwestern University Press. Original edition, 1995.

- 2008. Phénoménologie de la perception. Paris: Gallimard.

- 2010. Institution and Passivity: Course Notes From the Collège de France (1954-55). Translated by L. Lawlor and H. Massey. Evanston, IL: Northwestern University Press. Original edition, 2003.

- 2011. Child Psychology and Pedagogy: The Sorbonne Lectures 1949-1952. Translated by T. Welsh. Evanston, IL: Northwestern University Press.

- 2012. Phenomenology of Perception. Translated by D. A. Landes. Oxon,UK: Routledge. Morris, David. 2004. The Sense of Space. Albany, NY: State University of New York Press.

- 2005. Bergsonian Intuition, Husserlian Variation, Peirceian Abduction: Toward a Relation Between Method, Sense and Nature. Southern Journal of Philosophy 43:267298.

- 2008. Reversibility and Ereignis: On Being as Kantian Imagination in Merleau-Ponty and Heidegger. Philosophy Today SPEP Supplement:135-143.

- 2011. The Chirality of Being: Exploring a Merleau-Ponteian Ontology of Sense. Chiasmi International 12:165-82.

Odling-Smee, F. John, Kevin N. Laland, and Marcus W. Feldman. 2003. Niche Construction: The Neglected Process in Evolution, Monographs in population biology. Princeton: Princeton University Press.

Robert, Franck. 2006. Science et ontologie: Pour un concept renouvelé de nature. Archive de Philosophie 69:101-122.

Saint Aubert, Emmanuel de. 2006. Vers une ontologie indirecte. Sources et enjeux critiques de l'appel à l'ontologie chez Merleau-Ponty. Paris: Librairie Philosophique Vrin.

Sallis, John. 1973. Phenomenology and the Return to Beginnings. Pittsburgh: Duquesne University Press.

Tiemersma, Douwe. 1987. Merleau-Ponty's Philosophy as A Field Theory: Its Origin, Categories and Relevance. Man and World 20 (4):419-436.

Toadvine, Ted. 1999. Naturalizing Phenomenology. Philosophy Today SPEP Supplement:124131. . 2008. Phenomenology and "Hyper-Reflection". In Merleau-Ponty: Key Concepts, edited by R. Diprose and J. Reynolds. Stocksfield: Acumen Publishing.

- 2009. Merleau-Ponty's Philosophy of Nature. Evanston, IL: Northwestern University Press. 
Turner, J. Scott. 2000. The Extended Organism: The Physiology of Animal-Built Structures. Cambridge, Mass.: Harvard University Press.

Waldenfels, Bernhard. 2000. The Paradox of Expression. In Chiasms: Merleau-Ponty's Notion of Flesh, edited by F. Evans and L. Lawlor. Albany: SUNY Press.

Weele, Cor van der. 1999. Images of Development: Environmental Causes in Ontogeny, SUNY series in philosophy and biology. Albany: State University of New York Press.

Wilson, Robert A. 2005. Genes and the Agents of Life: The Individual in the Fragile Sciences, Biology. New York: Cambridge University Press.

Yuh, Chiou-Hwa, Hamid Bolourie, and Eric H. Davidson. 1998. Genomic Cis-Regulatory Logic: Experimental and Computational Analysis of Sea-Urchin Gene. Science 279:1896-1902. 